\title{
Effect of Murashige and Skoog Salts Strength Medium (MS) on Steroids Production and Total Amino Acids Content of Date Palm Embryonic Callus (Sakkoty and Bartamuda cultivar)
}

${ }^{2}$ Hussein A.Bosila,,${ }^{1,{ }^{*}}$ Sherif F. El sharabasy, ${ }^{1}$ Abdel-Aal W. B., ${ }^{2}$ Bayome M. Mansour and ${ }^{1}$ Abdel-Monem A. Bana

${ }^{1}$ The Central Lab of Date Palm Researches and Development, ARC, Egypt

${ }^{2}$ Floriculture, Medicinal\&Aromatic Plants. Dept., Fac. of Agric., Al-Azhar University, Egypt

asharabasydates@yahoo.com

Keywords: MS, steroids, amino acid, embryogenic callus, date palm

\begin{abstract}
The potential to use tissue culture technique for the production of some bioactive compounds is immense, since it allows the manipulation of the biosynthetic routes to increase the production and accumulation of specific compounds. This study was conducted to investigate the effect of MS salt strength on steroids production and total amino acids content in embryonic callus cultures of two cultivars of date palm (Sakkoty and Bartamuda). embryonic callus explants were cultured on MS (Full), 3/4 MS, $1 / 2$ MS and 1/4 MS), date was recorded every 6 weeks for three subculture. It obviously displays the superiority full MS over the three other investigated levels ( $3 / 4 \mathrm{MS}, 1 / 2 \mathrm{MS}$ and $1 / 4 \mathrm{MS}$ ) of steroids production (0.55, 0.38, 0.32 and 0.44 $45 \mathrm{mg} / \mathrm{g}$ dry weight respectively). Also the full MS level was the most effective of amino acids content $(0.95 \mathrm{mg} / \mathrm{g}$ fresh weight). Bartamuda $\mathrm{cv}$. was the superior of steroids production (0.45 $\mathrm{mg} / \mathrm{g}$ dry weight) and amino acid content (1.13 mg/g fresh weight) compared with Sakkoty cvs.
\end{abstract}

\section{Introduction}

Date palm, Phoenix dactylifera L. is a heterozygous and dioecious tree belongs to (Arecaceae) family. It is considered to be as the most significant fruit crop in the Arabian Peninsula and North Africa countries, where it is closely related to the life and culture of the people since ancient times [1]. In addition to the high nutritional value of fruits also there are economic benefits of the parts of the whole tree. It was found that date palm tissues are rich of phytosterols compounds [2,3]. It has been discovered by Arabs and Egyptians that date palm grains are considered as a cure for sterility or antsterility agent [4]. Steroids are a set of cholesterol derivative lipophilic that are low molecular weight and may found in synthetic sources. They are essential for standard growth, development and differentiation of multicellular of organisms. The animal sterols are coprostanol and cholesterol, and plant ones such as campestrol, ergosterol, and B-sitosterol [5,6]. Cholesterol is the chief animal sterol, that made to be in certain amounts in plants and found in oil, date palm [7]. Extraction of secondary metabolites for industrial application has become an attractive solution by biotechnological approaches [8]. El-Sharabasy [9] separated and identified cholesterol and ß-sitosterol from callus cultures by Thin Layer Chromatography (TLC). El-Sharabasy [10] found that embryogenic callus cells of date palm were stimulated greatly for steroids biosynthesis by the addition of the precursors. A number of chemical and physical factors influence biomass accumulation and synthesis of secondary metabolites in plant cell and organ cultures. Nutrient media components, growth regulators, $\mathrm{pH}$, 
temperature, light, etc... are considered to be the most important factors to enhance secondary metabolite accumulation in plant cell [11,12]. For the first time in this work the effect of MS basal medium (Murashige and Skoog) [13] salts strength on total steroids production and total amino acids content of embryonic callus stage of in vitro date palm Bartamuda, Sakkoty cultivars were studied in order to determine the optimal nutrient medium for enhancing accumulation of important secondary metabolites in date palm callus.

\section{Materials and Methods}

\section{Preparation of plant material}

Callus explants were produced from indirect protocol of date palm micropropagation discribed by Zayed [14] and El-Dawayati et al. [15].

Received embryonic callus explants for both Bartamuda. and Sakkoty cvs. were cultured on different levels of MS [13] salts strength, full strength of MS salts (Control), three fourth strength of MS salts, half strength of MS salts, and one fourth strength of MS salts. The basic nutrient medium components for all treatments are $30 \mathrm{~g} / \mathrm{l}$ sucrose and $3.0 \mathrm{~g} / \mathrm{l}$ activated charcoal with $40 \mathrm{mg} / \mathrm{L}$ adenine - sulfate, $200 \mathrm{mg} / \mathrm{l}$ glutamine, $100 \mathrm{mg} / \mathrm{l}$ myo-inositol, $0.1 \mathrm{mg} / \mathrm{l}$ biotin, 170

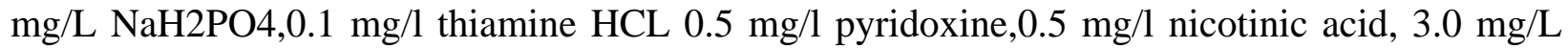
2- isopentenyl adenine (2iP) + $10.0 \mathrm{mg} / \mathrm{l}$ 2,4 -D dichlorophenoxy acetic acid (2,4 - D). Pyruvic acid was added at $0.01 \mathrm{mg} / \mathrm{L}$ to induce steroids compounds production [4]. $6.0 \mathrm{~g} / \mathrm{L}$ agar were used to solidified Culture medium which were distributed in culture jars $(250 \mathrm{ml})$; each jar contained $25 \mathrm{ml}$ of culture nutrient medium. Culture jars were immediately capped with polypropylene closure autoclaved at 121_C at $1.05 \mathrm{~kg} / \mathrm{cm} 2$ for $20 \mathrm{~min}$. The cultured jars were

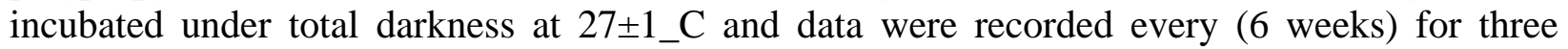
subcultures on total steroids content (mg/g dry weight).

1-Determination of total steroids (mg/g dry weight)

Total steroids were calculated as $\beta$-sitosterol and determined by spectrophotometer according to protocol described by El-Sharabasy and El-Dawayati [4] as follows:-

Test solution preparation: - $0.5 \mathrm{~g}$ weight of embryogenic callus sample is dried in an oven at 75 _C for $48 \mathrm{~h}$. dried embryogenic callus sample is placed in a clean flask, with addition of 100 $\mathrm{mL}$ of $5 \%$ potassium hydroxide solution in alcohol $(90 \% \mathrm{v} / \mathrm{v})$ and are heated on a water bath at 50_C to smooth reflux for 2 hours, then are cooled for $5 \mathrm{~min}$, then the flask contents are transferred to a separator funnel. The residual contents of flask were washed for two times, firstly with $100 \mathrm{~mL}$ water followed by $100 \mathrm{~mL}$ diethyl ether then the washings were transferred into the same separator funnel and they are shacked altogether slowly by hand for 3 min. To separate the formed layer the aqueous phase was removed from separator funnel. This layer was washed in a separator funnel four times with $100 \mathrm{~mL}$ diethyl ether then, is placed in a clean flask. The received ethereal extracts are washed with three successive portions of $40 \mathrm{~mL}$ water

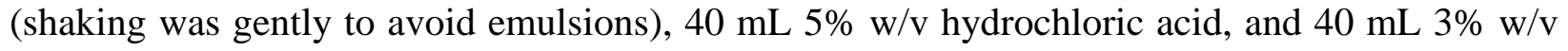
potassium hydroxide aqueous solution. Successive portions of $40 \mathrm{~mL}$ water (each wash) are edited until the washings become neutral to phenolphthalein solution (2 drops 1\% phenolphthalein in 70\% ethanol and $2 \mathrm{~N} \mathrm{NaOH}$ until rose color is stable). One drop of $0.1 \mathrm{~N} \mathrm{HCl}$ is added to sample and rapidly mix until the rose color disappears. $100 \mathrm{mg}$ anhydrous sodium sulfate powder is added to the sample with well shacking, then the mixture is filtered through folded Whatman filter paper. The resulted solution is evaporated in water bath at 50 _ $C$ until fully dry. $100 \mathrm{~mL}$ glacial acetic acid is added to the residue with stirring for $30 \mathrm{~min}$ in small glass bowl. 
Test solution: - $2 \mathrm{ml}$ of previous resulted solution is transferred to a $20 \mathrm{~mL}$ volumetric flask, and dilute to $20 \mathrm{~mL}$ with glacial acetic acid.

The reference solution preparation:- $40 \mathrm{mg} \beta$-sitosterol is dissolved in $100 \mathrm{~mL}$ glacial acetic acid then $5 \mathrm{~mL}$ of this solution is taken then diluted to $50 \mathrm{~mL}$ with glacial acetic acid.

The deniges reagent preparation: - This reagent is consist of mixing of two solutions (solution A) is prepared by adding $100 \mathrm{~mL}$ sulfuric acid to $50 \mathrm{~mL}$ glacial acetic acid..(solution B) is prepared by dissolving $5 \mathrm{~g}$ mercury oxide (HgO2) and $20 \mathrm{~mL}$ sulfuric acid into $100 \mathrm{~mL}$ water. $100 \mathrm{~mL}$ of solution (A) is added to $1 \mathrm{~mL}$ of solution (B), then are mixed and filtered through a sintered glass filter (grade G4) before use.

Finally $5 \mathrm{~mL}$ of Deniges reagent mixture solutions is added to test tube filled with $1 \mathrm{~mL}$ (Test solution) and $1 \mathrm{~mL}$ (Reference solution) for evaluation of $\beta$-sitosterol amount.

The blank is carried out by $1 \mathrm{~mL}$ glacial acetic acid instead of the sample in a test tube. Both tubes are lifted on the stand under the dark for $15 \mathrm{~min}$. The absorbance is read using a spectrophotometer at $510 \mathrm{~nm}$ against the blank reading. The amount of steroids is calculated as $\beta$-sitosterol from a standard curve prepared by dissolving $40 \mathrm{mg}$ of $\beta$-sitosterol in $10 \mathrm{~mL}$ glacial acetic acid. Series of standards are prepared as 5, 10, 20, and $40 \mathrm{mg} / 100 \mathrm{~mL}$, respectively; $1 \mathrm{~mL}$ of each is mixed with $5 \mathrm{~mL}$ Deniges reagent, and read at $510 \mathrm{~nm}$ against the blank. The absorbance of each concentration is plotted against the absorbance obtained from the standard curve.

Determination of total amino acids content (mg/g fresh weight)

Total amino nitrogen or free amino acids were determined according to Rosein [16].

\section{Statistical analysis}

The obtained data were subjected to analysis of variance. The mean values were compared using LSD test at the $5 \%$ level of probability. The data were tabulated and statistically factorial analyses according to the randomized complete block design with three replicates [17].

\section{Results and Discussion \\ Effect of different levels of MS salt strength on total steroids content (mg/g dry weight) embryonic callus date palm Sakkoty and Bartamuda cultivar in vitro.}

Data in Fig (1) showed that there are significant differences between different cultivars under investigation. The highest amount of total steroids was recorded was for Bartamuda cv. $(0.45 \mathrm{mg} / \mathrm{g}$ dry weight), while Sakkoty $\mathrm{cv}$. recorded $(0.40 \mathrm{mg} / \mathrm{g}$ dry weight $)$ of total steroids.. Referring to the specific effect of MS salts level it obviously displays the superiority of the highest level (full MS) over the three other investigated levels ( $3 / 4 \mathrm{MS}, 1 / 2 \mathrm{MS}$ and $1 / 4 \mathrm{MS}$ ). Concerning, the interaction between MS salt levels and cultivars, it was noticed that, Bartamuda cultivar grown on full MS salt strength formed the highest significant value $(0.57 \mathrm{mg} / \mathrm{g}$ dry weight) of total steroids. On the light of our results it has been reported that medium manipulation is the most fundamental approch in plant tissue culture technology [11]. Murashig and Skoog is one of the most commonly medium were used for plant in vitro cultures, the high concentrations of nitrate,potasium and ammonium is the significant feature of Murashig and Skoog medium, nitrogen concentration was found to affect the amount of secondary metabolits in plant cell cultures as it has an regulation role for the expresstion of specific protiens through mechanisms affecting m RNA stability and transcription. Also, phosphour have important effect on the production of secondary metabbolites in plant cell cultures [18]. Which is confirmed with our results that the full MS salt strength of high concentration of total nitrogen and phosphour gave the highest signficant results of total steroids production in date palm callus. 


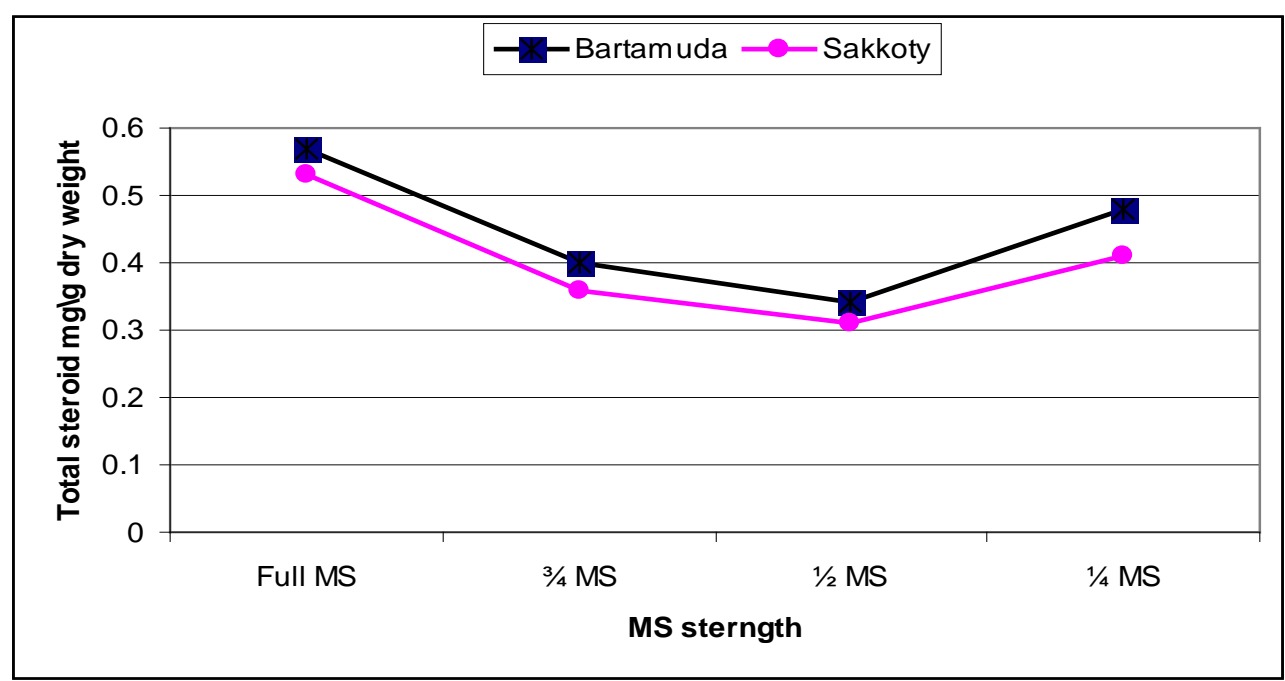

Fig. 1: Effect of different levels of MS salt strength on total steroids content ( $\mathrm{mg} / \mathrm{g}$ dry weight) of embryonic callus date palm Sakkoty and Bartamuda cultivar.

Effect of different levels of MS salt strength on total amino acids content (mg/g fresh weight) of embryonic callus of date palm Sakkoty and Bartamuda cultivars.

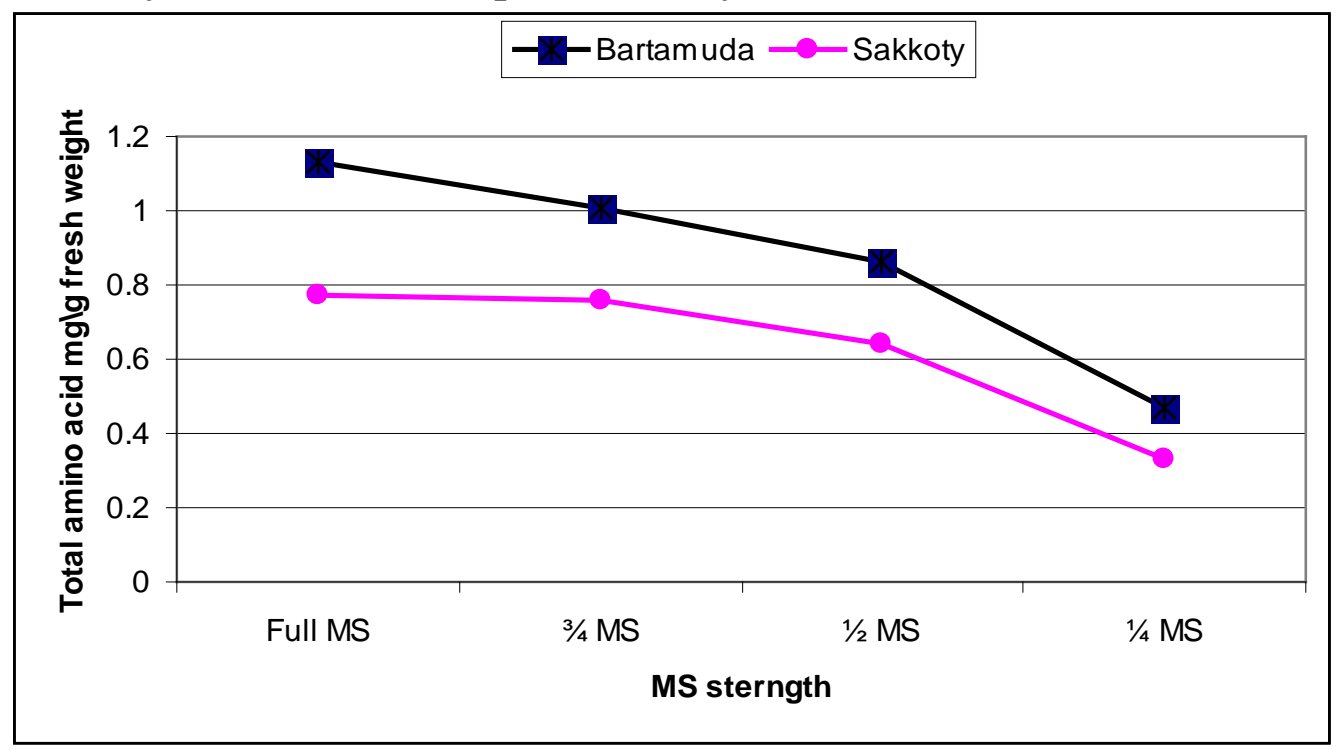

Fig. 2: Effect of MS salt strength on total amino acids content ( $\mathrm{mg} / \mathrm{g}$ fresh weight) in embryonic callus stage of date palm (Sakkoty and Bartamuda cultivar).

Data in Fig. (2) indicated that, there were significant differences between the two cultivars under investigation in total amino acid from embryogenic callus $(0.87$ and $0.62 \mathrm{mg} / \mathrm{g}$ fresh weight respectively). It was also observed that the full MS concentration was the most effective as it induced $0.95 \mathrm{mg} / \mathrm{g}$ fresh weight of amino acids while other concentrations $(3 / 4 \mathrm{MS}, 1 / 2 \mathrm{MS}$ and $1 \frac{1}{4}$ MS respectively) formed $0.88,0.75$ and $0.40 \mathrm{mg} / \mathrm{g}$ fresh weight respectively.

Concerning the interaction between cultivars and MS salt concentrations, the results illustrated that the highest significant value was of total amino acids $(1.13 \mathrm{mg} / \mathrm{g}$ fresh weight) was for Bartamuda cultivar was formed by embryogenic callus grown on full MS medium. The lowest value $(0.33 \mathrm{mg} / \mathrm{g}$ fresh weight) of total amino acids was formed by Sakkoty cultivar 
embryogenic callus grown on medium contained 1/4 MS. The present results regarding the influence of MS medium on total free amino acids content was in general agreement with the finding of Mohamed [19] who decided that total amino acids significantly differed between cultivars and the highest amino acid content was detected with Bartamuda followed by Sakkoty.

\section{Summary}

Date palm steroids production from callus cultures seems to be an important approch for various studies depend on the manipulation of nutrient medium.

\section{References}

[1] D.V. Johnson, J.M. Al-Khayri, S.M. Jain, Introduction: Date production status and prospects in Asia and Europe. In Date palm genetic resources and utilization, Springer, Dordrecht, 2015, pp. 1-16. https://doi.org/10.1007/978-94-017-9707-8_1

[2] S.F. El-Sharabasy, Studies on the production of secondary metabolites from date palm by using tissue culture technique: Ph.D. Thesis, Fac Agric, Al-Azhar University, Cairo, 2000, pp 200.

[3] S. Besbes, C. Blecker, C. Deroanne, N. Bahloul, G. Lognay, N.E. Drira, H. Attia, Date seed oil: phenolic, tocopherol and sterol profiles. Journal of food lipids 11-4 (2004) 251-65. https://doi.org/10.1111/j.1745-4522.2004.01141.X

[4] S.F. El-Sharabasy, M.M. El-Dawayati, Bioreactor steroid production and analysis of date palm embryogenic callus, In: J.M. Al-Khayri, S.M. Jain, D. Johnson (Eds), Date palm biotechnology protocols, Tissue culture and applications, Humana Press, New York, 1 (2017) 309-318. https://doi.org/10.1007/978-1-4939-7156-5_25

[5] D. Lednicer, Steroid chemistry at a glance. John Wiley \& Sons, 2011.

[6] A. Sultan, A.R. Raza, Steroids: a diverse class of secondary metabolites, Med Chem 5-7 (2015) 310-317.

[7] Z.G. Brill, M.L. Condakes, C.P. Ting, T.J. Maimone, Navigating the chiral pool in the total synthesis of complex terpene natural products, Chem. Rev. 117-18 (2017) 53-95. https://doi.org/10.1021/acs.chemrev.6b00834

[8] F. Biglari, A.F. AlKarkhi, A.M. Easa, Antioxidant activity and phenolic content of various date palm (Phoenix dactylifera) fruits from Iran. Food chem 107-4 (2008) 1636-41. https://doi.org/10.1016/j.foodchem.2007.10.033

[9] S.F. El-Sharabasy, H. Bosila, S.Mohamed, I. Ibrahim, K. Refay, Production of some secondary products from date palm (Phoenix dactylifera) tissue cultures, Sewi cultivar using some precursors during Embryogenesis stage, Second Emirates conference of date palm, Abu Dhabi (2001) 540-545.

[10] S. F. El-Sharabasy, Effects of some precursors on development of secondary products in tissues and media of embryogenic callus of date palm cv. Sewi. Arab J. Biotech 7 (2004) 83-90.

[11] A.P. Ling, S.L. Ong, H. Sobri, Strategies in enhancing secondary metabolites production in plant cell cultures, Med Aromat Plant Sci Biotechnol. 5 (2011) 94-101. 
[12] E.M. Abd El-Kadder, I.I. Lashin, M.S. Aref, E.A. Hussian, E.A. Ewais, Physical elicitation of ( Dillenia indica) callus for production of secondary metabolites, New York Sci J, 7-10 (2014) 48-57.

[13] T. Murashige, F. Skoog, A revised medium for rapid growth and bioassays with tobacco tissue cultures, Physiol. Plant 15 (1962) 473-497. https://doi.org/10.1111/j.1399-

3054.1962.tb08052.x

[14] Z. E., Zayed, Enhanced Indirect Somatic Embryogenesis from Shoot-Tip Explants of Date Palm by Gradual Reductions of 2, 4-D Concentration, In Date Palm Biotechnology Protocols, Humana Press, New York 1 (2017) 77-88. https://doi.org/10.1007/978-1-4939-7156-5_7

[15] M.M. El-Dawayati, H.S. Ghazzawy, M. Munir, Somatic embryogenesis enhancement of date palm cultivar Sewi using different types of polyamines and glutamine amino acid concentration under in-vitro solid and liquid media conditions, Int J Biosci, 12 (2018) 149-159. https://doi.org/10.12692/ijb/12.1.149-159

[16] H. Rosein, A modified ninhydrincoloremetric analysis for amino acids, Archives of Biochemistry and Biophysics 67 (1957) 10-15.

[17] G.W. Snedecor, W.G. Cochran, Statistical Methods, Oxford and J.B.H. Publishing Co. 6 (1980) 507.

[18] W. Yue, Q.L. Ming, B. Lin, K. Rahman, C.J. Zheng, T.Han, L.P. Qin. Medicinal plant cell suspension cultures: pharmaceutical applications and high-yielding strategies for the desired secondary metabolites, Critical reviews in biotechnology, 36-2 (2016) 215-32.

https://doi.org/10.3109/07388551.2014.923986

[19] A.M. Mohamed, Resistant cellulars selection of some date palm varieties through new genetically techniques: Ph.D thesis, Department of Agricultural Botany Fac. Agric., Al-Azhar University, 2008, pp. 53. 